MedieKultur | Journal of media and communication research | ISSN 1901-9726

\title{
Paradox and pleasure: \\ Play with everyday life in a ludic simulation
}

\section{Sara Mosberg Iversen}

MedieKultur 2014, 56, 100-116

Published by SMID | Society of Media researchers In Denmark | www.smid.dk The online version of this text can be found open access at www.mediekultur.dk

Media use is a mundane activity that may nevertheless be highly pleasurable. Here, the focus is on the articulated pleasures of playing the digital games The Sims 2 and The Sims 3. The paradox that relieffrom everyday chores is found in a game that, to a great degree, simulates similar activities is analysed on the basis of 13 online or email qualitative interviews. The analysis employs the concepts of realism and fantasy, which have been used to understand media pleasures as concerned both with the familiar and the utopic. While realism in some form or other appears important to most of the informants, the point of recognition is not the portrayal of daily routines but rather relationships and places. These "realistic" elements form a bridge to utopic engagements - most strikingly, an oscillation between being in and letting go of control.

The everyday offers itself up as a problem, a contradiction, a paradox; both ordinary and extraordinary, self-evident and opaque, known and unknown, obvious and enigmatic. (Highmore, 2002a, p. 16)

\section{Introduction}

In his Everyday life and cultural theory (2002a), Ben Highmore portrays everyday life as inherently ambiguous. It is right there and nearly ungraspable at the same time, tedious and full of wonder, comfortable and unbearable. It can be argued that it is precisely the 
contradictions of the mundane that lie at the centre of many popular media texts from Breaking bad (Gilligan, 2008), women's magazines, and super-hero comics to the sharing of snapshots on networked services such as Instagram.

While it is important not to romanticise the pleasures of media use - for instance, by regarding polysemic readings as instantaneously emancipatory or online participation as automatically empowering, it is likewise vital to consider the pleasures of popular media use for what they are and mean to those who engage with these texts in various ways particularly, in order to confront the politics of everyday life, which often are not very visible or spoken of explicitly (Highmore, 2002b, pp. 4-8). Joke Hermes, on the basis of work by Toby Miller (2007) and John Ellis (2000), argues that popular culture is a prominent site for enacting cultural citizenship (2005, pp. 1-17). In Hermes' vision, popular culture enables its users to belong and to fantasise as well as to bridge the private and the public (Hermes, 2005, p. 3). Here, between the disciplining of popular texts and the self-determinism of meaning-making, it becomes possible to express and negotiate values and nearly invisible norms, to engage in politics disguised as matters of popular culture and everyday living.

One popular media text that is concerned with everyday life in its variety of guises is The Sims (TS) (2000) series with its many updates and sequels. Perhaps not surprisingly, in the accounts of gameplay that underlie this analysis, the use of these games appears rife with ambiguities, particularly in relation to conceptions of and perceived relations to everyday life. On the basis of 2 email and 11 online group interviews on a private blog with 13 self-selected adult players of The Sims 2(TS2) (2004) and The Sims 3 (TS3) (2009), the intention here is to examine a paradox that appears in the qualitative material: namely, that relief from the chores of work and family life is found in playing two games that, to a great degree, simulate activities similar to those from which the players seek a respite. Drawing on notions of realism and fantasy that, according to Barbara O'Connor and Elisabeth Klaus (2000), are regarded as central elements of media pleasure, I will try to make sense of this interesting paradox. First, media pleasure is discussed, followed by a brief introduction to the TS series and the online community that has emerged around these games. Methodology is also considered before launching into the analysis.

\section{Media pleasures}

A long-lived dividing line in Media Studies can be drawn between notions of active, even oppositional, audiences and their media-derived pleasures, on one hand, and the concerns about exploitation and dominance of audiences through media production and circulation, on the other. Although it is possible to find both blatantly celebratory as well as one-sidedly alarmist takes on today's media landscape, there is also abundant attention to tensions and ambiguities. This underlines the complexity of media use, suggesting that reception and response shape and are being formed by conflicting forces, motivations, and emotions. Media use is precisely open for exploitation because it is highly pleasurable, not 
the least due to the potential for co-construction through interpretation as well as fannish appropriation (Fast, 2012, pp. 43-44).

In their discussion of the scholarly treatment of media pleasures, O'Connor and Klaus (2000, p. 376) highlight two recurring elements, namely, realism and fantasy. With a reference to Pierre Bourdieu's work, O'Connor and Klaus stress that the pleasure of the popular is the enjoyment of recognition (2000, p. 372). len Ang (1991) likewise emphasises both the familiarity of the domestic setting as well as the emotional realism of the soap opera, which enables viewers to understand and identify with the on-screen characters and their narratives. Importantly, realism here should not be understood in a strictly formal sense as referring principally to particular schools of aesthetics within painting, literature or film. While residue from these disciplines may well be forming everyday notions of realism, the concept of "realism" here primarily signifies (mundane) life as the individual knows it in a manner that appears similar (enough) to be easily relatable, knowable, or understandable.

If realism marks one side of media pleasure, fantasy belongs on the other ( $\mathrm{O}^{\prime} \mathrm{Connor} \&$ Klaus, 2000, p. 376). The notion of fantasy refers both to excesses and fantastic elements in the texts themselves, as well as to the day dreaming, wish fulfilment, or speculative experiments to which engaging with these facets may give rise. Hermes, for instance, discusses how the reading of women's magazines lets the users imagine an "ideal self" (1995, pp. 39-41), while Janice Radway treats romance reading as a way- via fantasy - briefly to escape but not challenge patriarchal society (1991, pp. 86-118). One way to understand these acts of imagination, and this is mainly where my focus will be, is to regard them as an engagement with the utopic:

Entertainment offers the image of 'something better' to escape into, or something we want deeply that our day-to-day lives don't provide. Alternatives, hopes, wishes - these are the stuff of utopia, the sense that things could be better, that something other than what is can be imagined and maybe realised. (Dyer, 1986, p.177)

Importantly, Richard Dyer maintains, entertainment does not provide visions of utopias, instructions for how to achieve and organise this state, but rather a sense of "what it would feel like" (Dyer, 1986, p. 177). If the utopic element inherent in popular entertainment primarily provides sensations, what are these, then? Dyer suggests five central emotions based on Georg Kateb's (1963) discussion of dominant motifs in Western utopian thought (Dyer, 1986, pp. 180-181):

- Of energy, which implies both capacity for high activity as well as the power to act.

- Of abundance, referring both to sensuous experience and lack of scarcity.

- Of intensity, as in strong, involved emotions lacking in ambiguity.

- Of transparency, that is, sincere relations between the agents involved.

- Of community, which implies a sense of belonging, a confirmation of relationships. 
Dyer presents these traces of the utopic as entertainment media's answer to the real (rather than false) needs of people, needs that, to a great degree, emerge as symptoms of the modern, capitalist order. In Dyer's view, engagement with these utopian elements does not bring any real change. It is an offering of stones rather than bread as capitalist society promises to remedy itself through its entertainment media (Dyer, 1986, pp. 184-185). However, it has been argued that it is not fruitful to judge the fantastic element of pleasure solely as a means to an external end in the form of immediate and radical societal change (Harrington \& Bielby, 1995, pp. 119-153; Kaplan, 1986):

\begin{abstract}
Whatever the concrete reasons for women taking pleasure in this [romance reading] - here some further ethnographic inquiry could provide us with new answers - it seems clear to me that what is fundamentally involved is a certain determination to maintain the feeling of romance, or a refusal to give it up, even though it may be temporarily or permanently absent in "real life", against all odds. And it is this enduring emotional quest that, I would suggest, should be taken seriously as a physical strategy by which women empower themselves in everyday life, leaving apart what its ideological consequences in social reality are. (Ang, 1998, p.1988)
\end{abstract}

While engagement with utopic elements in popular culture may lead to reflection and action, the utopias implied by Ang above do not require actualisation in order to be deemed acceptable. Fantasising here is, rather, portrayed as a necessary element of being a functioning human being.

\title{
Games of everyday life
}

Diane Nutt and Diane Railton (2003) suggest in their analysis of TS (2000) that the game does not fit within existing genre categories, requiring players to make sense of it on the basis of their experience with the mundane. While this treatment does not take into account the game's fantastic or exaggerated content or many players' experimentation with and enjoyment of these elements, it does capture a central feature of the whole game series: its focus on and continual reference to Western (middle class) everyday life.

With a basis in a household of one of more simulated people, the Sims, players get to manage the day-to-day lives of their virtual charges. It is up to the player to decide how the Sims she controls should divide their waking time between work, socialising, fun, skilltraining, and the like. This process is made difficult because Sims have basic requirements for nutrition, sleep, hygienic care, entertainment, and socialisation; needs that can only be overlooked for so long before a Sim gets depressed or wets himself. Sims are, likewise, defined by traits, wants and fears of different kinds. While traits can be assigned by players to the Sims they create, the derived wants and fears are mainly designated by the game engine. All these variables affect each other in various ways, together determining the "personality" of a given Sim. As virtual agents, Sims act according to their needs, wants and fears and, likewise, relate to other Sims on this basis. The player-controlled household is, 
namely, part of a larger neighbourhood populated by game-controlled Sims who, likewise, interact according to their game- or player-defined personalities. Depending on inclination, players may either micromanage their Sims' lives or, to a greater or lesser degree, let the game control even the playables. On this basis, Sims may, more or less, take on "a life of their own", something many players in this study find great enjoyment in.

Apart from the gameplay of handling or watching Sims, the games offer players an opportunity to construct everything from Sims to houses and worlds, not to mention user-created content ranging from skins to larger software modifications (Sivhonen, 2011; Wirman, 2011). Partly due to the modding culture that has arisen in relation to the games, participation in one of more of the many user-created fora dedicated to the game series is a central and important facet of playing for many adult players. Players also socialise online to share their playing and to learn more about the games from the global community. Playing the games, then, may mean rather different things to different players.

\section{Articulations of gameplay experience}

The basis for this study is several years of participation in the community around the games. The 2 email and 11 online group interviews discussed here are, thus, grounded in a shared practice. Throughout my years active in the community, I have observed that teenage players of TS2 and TS3 are more likely to play with physically co-located friends, while most adult players primarily share their passion for the TS series with others online. The main site of social engagement for the adults is not a physical location; and, if one wants to engage these players for a study, the most viable mode of access is via the Web (Kivits, 2005, pp. 35-36; Kozients, 2010). While online participation is both a practical form of access to the global online community formed around the TS series as well as in line with how the adult players primarily interact (Hine, 2000, pp. 48-50), a purely netnographic approach (Kozinets, 2010) naturally has its limits. Participants are not encountered in a shared time and space but only through written accounts and, in some cases, images. Consequently, it is articulations of self, practice, and everyday living that will be analysed here. While the participants' reflections and descriptions are formed in hindsight and not necessarily an expression of what actually transpires through gaming sessions, these accounts are still performative, shaped by and shaping a shared practice. In order to retain the playful and informal tone of the exchange, all citations from the interviews appear as they were typed by the informants, apart from any changes I have made to secure the participants' anonymity (see note 1).

This study does not intend to account for the culture around the TS series in all its variety and richness. While previous studies have focused on users' modifications of the games and the creation of customised content (Sihvonen, 2011; Wirman, 2011), it has been the aim here to focus on a group of dedicated adult players who define themselves as "general players" rather than modders only. Hence, the 13 participants have been recruited through an open call for participants at a well-established, very active members-only, inter- 
national general forum dedicated to the game series. ${ }^{1}$ They are all long-time players and highly invested in and knowledgeable about the games and their mechanisms. ${ }^{2}$ That is, these players use, maintain, modify and keep themselves informed about a complex piece of software with a sophisticated Al. All identify as females, most over the age of 30 . While the forum in question does have members who identify as males, the participants here are typical of the forum both in terms of gender, age, and preferred playing styles. It is observable that other fora dedicated specifically to the creation of game modifications or the sharing of user-created content, such as moreawesomethanyou.com or modthesims.com, have a much larger proportion of male members. That the game series has given rise to a great number of diverse fan fora with different foci attests to the flexibility of the games both in terms of modification-friendliness and possibilities for gameplay.

The majority of the informants describe their gameplay as character- and story-driven. Likewise, all informants stress the importance of socialising around the game, portraying this as a central element of their gaming activity. Thus, it is appropriate to describe the majority of informants' use of the games in terms of the immersion category of the committed mentality profiles detailed in the Intensity Sociability Game Model (Kaillio, Mäyrä \& Kaipainen, 2011: 336-338). This category is characterised by long, intense stretches of playing time with a focus on story and character. While playing itself is solitary, the players still stress the importance of socialising with others around the game. This kind of playing shares some similarities with the style of dedicated role-players in being directed at character and story (see for instance Tychsen, Brolund \& Hitchens, 2008). Yet, the informants here do not role-play but rather regard themselves as directing different characters in a story. Terms like "author", "god" and "director" are typically used when these players describe the relation to their Sims. In this regard, and considering the widespread building or customisation activities likewise involved in playing, the informants' creative uses and reconfigurations of the games bear many similarities to other fans' appropriations of popular media texts (Fiske, 1992; Jenkins, 1992).

The semi-structured online or email interviews that form the core of this study have been conducted during the fall of 2011, focusing broadly on the players' experience of playing TS2 and TS3. This has resulted in incredibly rich material with regard to Sims, love, construction and learning, as most participants shared readily about their playing and how they understand this activity in relation to their everyday life. The theme of this article has emerged through an initial inductive and simultaneous coding (Miles, Huberman, Saldaña, 2013, pp. 73-90). In order to refocus on the paradox at play here, the empirical material has subsequently been re-coded with a predefined, theoretical focus on media pleasure, reality and fantasy as well as everyday life.

\section{Everyday life as a context for playing}

Apart from sharing a passion for the TS series, the players participating in this study are different in many respects. One or two are students; many have full time jobs of which a 
few are highly-demanding career positions. Others are retired, self-employed or full-time housewives. Some have children, others not. Some are single; others are in relationships; some live alone; some live with others. One thing that unites the majority of the informants, however, is an everyday life with many different responsibilities and chores:

\begin{abstract}
I have a full time job and two sons (10 and 12). Some days it is crazy, busy and stressful. When I find some alone time towards the end of the evening, I turn to my sim game. Sometimes I see a story line or photos and I think "I miss my sims!!" or "that gives me an idea" ... and off I go. (Betty)
\end{abstract}

I find playing the sims a relaxing way to deal with stress. I have been caring for my elderly mother for the last ten years and when I start my game all the stressors of being a caretaker seem to fade away. (Anna)

Betty and Anna, without being prompted, immediately insert their playing into a taxing everyday context with work outside and/or in the home. This is a theme presented with variations by a majority of the informants. At the same time, it is clear from the interviews as well as my forum interaction with the participants that these descriptions of demanding everyday lives are partial pictures of fairly ordinary, even "good", lives. Yet, in contextualising their use of TS2 and TS3 in relation to their life situation, the informants often relate it to stressful aspects: difficult colleagues one can do nothing about, balancing the care for others with care for oneself, managing isolation due to particular family circumstances, coming to terms with loss and illness, the stress of managing job and family, or getting through a particularly bad bout of depression:

I play as a way to escape reality for a while. Unlike most of my 'creative' hobbies, Sims can usually manage to put $90 \%$ of my overacive brain to work, thinking up the story, looking for picture moments, etc.

I have to admit that when I'm particularly depressed, it's not a matter of 'having time' but of 'making time' - I will neglect other things in order to play Sims sometimes... (Gerd)

Playing the games in relation to this catalogue of everyday difficulties is described as a great pleasure and, in many cases, as a (nearly meditative) respite. It is possible that this positioning of gaming in relation to everyday life appears because the informants feel a need to defend their playing in the interview situation. If this is the case, it is most likely due to more general expectations related to women's leisure time (Winn \& Heeter, 2009) rather than my presence as an interviewer. From my engagement in the community, these players know me as a fellow player, not only as a researcher.

When asked late in the interviews whether playing the game is time well-spent or something to be ashamed of, most of the informants declare their right to spend their free time on whatever they want rather markedly. Yet, some also express mixed feelings - for 
instance, Felicity, who feels torn between spending time on knitting and playing. Interestingly, she stresses that "the conflict is my own". Later, she elaborates:

\begin{abstract}
When I Sim, I don't feel that I have created anything tangible. My little digital world is enjoyable, and I have had a few families I became very attached to, but in the end, I feel no guilt in abandoning a world or a family for a new world and new family. If on the other hand I was a designer or a builder, and created objects, lots, etc. for others, I would feel that I was creating something tangible. For me, something tangible means an end product and for my own style of gaming, I don't have an end product. (Felicity)
\end{abstract}

Although Felicity stresses that the conflict of whether to play or not is her own - meaning that there is no direct external pressure not to play, it is clear here that dominant notions of being useful or achieving something tangible with one's time play a role in the (personal) negotiation over the proper use of free time. Another informant, Joan, mentions Weber's notion of the Protestant ethic (Weber, 2011) when discussing her issues with taking time out to play. In fact, the very forcefulness with which several of the informants state their right to determine their leisure time can be regarded as a reaction against competing views on how adults (and, in particular, women) should spend their free time.

In the accounts, the use of TS2 and TS3 is portrayed as a deliberately constructed space of one's own (Iversen, 2013). A paradox appears, then, in that relief from the demands of the mundane is found in a game that seems to simulate these same chores and responsibilities and, importantly, directly implicates the player in them through the potential for configurative effort. One way to understand this seeming paradox is to look at it through the lens of media pleasures and the notions of realism and fantasy.

\title{
Realism: Basis for recognition and identification
}

As already stated, TS2 and TS3 may be understood as games that simulate Western everyday life. This lends the game series an initial recognisability:

I was first attracted by the "simulation life" of the Sims 1, but with time, it's the "creativity" that made the Sims games so enjoyable for me. (Joan)

Even when simulation of the mundane does not continue to be the main attraction, the familiarity of the setting seems explicitly (as in the case above) and more implicitly to be central in drawing in the new players.

Although it can be argued that slapstick humour and cartoonish looks make the games more a parody than a realist portrayal, notions of realism generally abound in the informants' discussion of the games. A few are highly invested in the idea of playing a realistic game - for instance, Dorothy, Katherine and Irene, who assess game elements and alter, supplement and reinterpret mechanics on the basis of whether this contributes to their perception of a realistic universe. The majority appear to enjoy the games' mix of more 
true-to-life, cartoon-like and fantastic elements, while yet another small group, Eva and Marion, more or less (though not fully) discard "realism" as an important reference point.

Whether or not players enjoy a primarily "realistic" game, the day-to-day routine of Sims is never mentioned as an aspect that contributes to recognition. The "eat/sleep/pee/get married/get to the top of your career routine", as Katherine calls it - and several other players use similar expressions - is, in fact, only mentioned as an example of unimaginative and, implicitly, novice gameplay.

The simulated everyday routines, despite their - one should think - immediate recognisability, are only presented negatively and not as something with which informants express a conscious identification. Instead, two other elements seem to make the games relatable and familiar. The one that is articulated as most important by nearly all informants is the Sims' human-like qualities. Their ability to act upon individual motivations, express themselves and relate to other Sims, which make them appear to have a kind of emotional realism (Ang, 1991, 474):

\begin{abstract}
[...], looking at Belinda and Raul, their wants and their goals (LTWs), I'm not sure if they'll last either. If I were playing my "old" way (where I did the eat/sleep/pee/get married/get to the top of your career routine), I wouldn't have even thought of this possibility. Belinda and Raul, seeing that they're always autonomously interacting with each other, would have just gotten married and lived happily ever after with each other. But, since they rarely roll wants for one another anymore, I'm starting to wonder if they aren't "meant to be" afterall. What if there is someone else out there that they'd be more passionate about but they'll never know because I'm not letting them explore? (Katherine)
\end{abstract}

Katherine here speaks of agents with life projects and emotional needs rather than entities who eat and pee, and hers is a typical example rather than an exception. As the rest of her interview shows, this is not due to any naivety on her part; she - like the rest of the informants - is fully aware of the degree to which they endow Sims with rich inner lives. The games, unlike most other digital games, simply offer the perfect mix of mechanics for making the Sims' appear particularly human. Definers such as traits, wants and fears enable this as does the possibility for high autonomy. See Iversen (forthcoming) for a thorough treatment of this topic.

The other central "realistic" element is the ability to construct intricate, authentic-looking buildings. Marion, for instance, expresses her enjoyment of recreating period buildings even though she clearly finds the notion of "realism" problematic for many reasons. Many of the informants, in fact, care about creating "realistic" buildings, even when they mix styles and elements without seeking an overall realistic look:

Though this world is made of various European architecture, it's still kind of coherent; there's no skycrapper, for example. But there's an Eiffel Tower on a beach... My mind can accept 
the second but not the first one; the Eiffel Tower has something a bit ridiculous and so a bit funny, while I don't see anything funny with a skyscrapper. :) (Joan)

The notion of "kind of coherent" that Joan brings up here aptly describes the ways in which most of the informants lay out their game worlds on the basis of their familiarity with certain town types, building styles and historical periods.

Interestingly, the realistic elements in the games that the majority of the informants articulate as significant are, to a great degree, the product of customisation, such as redecorating a pre-made game world or building one's own or adding another layer of meaning to the mechanistic daily routines of eating, working and sleeping. The rather cartoon-like universes that come with the games are - at least, to some degree - reconfigured to appear to be more realistic and, by implication, relatable to the individual player. For Dorothy, for instance, this may mean creating career-themed lots; Gerd makes sure that her families always eat dinner together even though this is not something that is strictly required; Joan has changed an American-flavoured pre-made world into something more European, while, for Felicity, it is a matter of maintaining a degree of uniformity in her various, differently-themed worlds.

Most importantly, while the games may be regarded as simulations of everyday life as the Western middle class knows it, the informants' focus indicates that relationships and the places in which they play out - homes and public buildings - are the vital elements. Despite the games' focus on mundane chores and basic needs, these players choose to focus on more existential projects and desires - to belong, to become, to love. It can be argued, then, that the game elements considered realistic by the informants enable them to defocus from the drudgery of everyday life, however pronounced this theme is in the games. Instead, what captivates - or, as Dorothy says, "the more important gameplay" - is the relationships as well as special aspects of everyday living: falling in love, getting a promotion, seeing children grow up, putting one's mark on things. In this regard, the realistic elements of pleasure can be seen as a bridge to fantasy, which enables players to reach out towards what is dreamed of or hoped for from a foundation of the familiar and relatable.

\section{Fantasy: Reaching for something better}

TS2 and TS3 provide a perfect setting for playing out fantasies. While utopic elements appear as an explicit theme in most of the informants' descriptions of their use of the two games, accounts of personal fantasies are scarce. The player who is most pronounced about the fantasy element of her game is Eva. Her descriptions and pictures present an artistic, dream-like tapestry of scenes in which the Sims quest for true love and beautiful bi-sexual males abound: 
movements and flexibility. They are usually made of synthetic resin and hand painted. They are usually incredibly beautiful. (Eva)

Eva's game, then, is about beauty and "true love", constructed from a very personal vision and, apart from a focus on Sims' emotional realism, seeking to escape the bounds of the actual rather than mirroring external reality. Hers is, however, not the only account in which Sims' search for "true love" is a primary focus. This is something in which most of the informants are highly invested:

Well my favorite couple would have to be the ones i am playing right now... What do i like about it....They are totally opposite from one another.... Bernie(male) does not like kids or electronics....yet my game made his wife get the "have a baby moodlet" ....Needless to say until the child reaches teenage level their relationship is poor.... Now with Alice(female)...she loves kids...and the outdoors...and electronics... Now with all their little differences....when i play just the kid and let everything go.....all the sudden i zoom in on those 2 kissing....lts like being told your a good match-maker.... (Lisa)

With regard to a question of perfect matches or, as in Lisa's case, intentionally bad matches that work despite all odds, I see the focus on romantic love in the informants' accounts as primarily engagement with the utopic - in particular, an exploration of, a reach for intensity and transparency (Dyer, 1886, pp. 180-181). In the case of TS2, transparency in relations even becomes quite literal because the game offers mechanisms for gauging Sims' attractions. This puts players in a position in which they get more or less full insight into the internal intricacies of relating and loving. In contrast, the affective work in the everyday household rarely takes place under such opaque circumstances.

Another utopic element mentioned by several players is the option the games give for not letting Sims age or die:

It may be that I am so uncomfortable with dying sims due to the fact that I do not take death and loss in "real life" very well at all. I had no control that my father was taken from us at such an early age, or my nephew who passed away due to crib death at 3 months old ... or even the dog I so loved who died this year. At least with this silly game ... I do not have to let go .. if that makes any sense to you. (Betty)

In the above passage, Betty directly links the utopic element of letting Sims live on forever to her experience of loss in the family. In her interview, she even talks at length about a pre-made Sim family with a widow, Brandi Brooke, whose husband, the game informs us, has died in a swimming pool accident. She not only deletes the pool but also recreates the husband, Skip, and takes great pleasure in playing this family. Through the fantasy, which the game lets her act out, Betty takes back the control she did not have over death in her own life. Another player, Joan, explains how she has shied away from having elderly Sims in her game because that would remind her too much of her deceased and dearly-loved grandparents. Little by little, she has gone from having only mean and grumpy elders in 
her game to having nice but single elders. She still does not have any nice elderly couples but hints that even this may be possible in the future. These are two examples of how the informants use the games to come to term with death through fantasy. Importantly, the issue sat the centre here - the deceased loved one and the horrifying finality of death - are being engaged and handled rather than glossed over or avoided.

Another interesting engagement with the utopic made possible by the games is mentioned explicitly by two of the informants, namely, the possibility of consuming without seemingly consuming. Here, the players avoid buying and owning "stuff" for political or practical reasons, finding an outlet for their aesthetic and consumerist urges in the simulation. It is a fantasy, then, of not using resources, of escaping consumer society, which is engaged in through simulated (as well as actual) consumption. This is, then, on the one hand, a way to enjoy boundless abundance without incurring most of its side-effects while, on the other hand, it is also a critically informed act, a struggle with one's positioning as a consumer and with the desires so easily fuelled by consumer society.

The last and most dominant recurring engagement with the utopic in the interviews is related to control but not in any simplistic or one-directional sense:

I love leaving a latitude to my Sims. I wouldn't like controlling everything, as it would have little interest to me, but on the other hands, I don't want to play with Story Progression going on, because I don't want my Sims doing things without me. They can surprise me, but I have to be the witness of their actions to enjoy them. :) (Joan)

Nearly all informants, like Joan above, describe their playing in different ways as an oscillation between being in control and letting go of control. The utopic element of the control the games offer players is quite clear. Playing the games allows the player to be a kind of god or author who may micromanage her Sims and their universe to a rather high degree. The experienced player does this on the basis of a vast knowledge of the games' mechanisms and intricacies. It is a kind of transparency, which further underlines the utopic element - that one may be in control on the basis of more or less perfect knowledge. While the ability to control, order and manage may be the first impulse, a novice strategy, as the interviews often imply, letting go of control for this group of players is the second step of the control fantasy:

He [Thomas] had a ton of adventures, including being bitten by a vampire neighbour, but the fun thing was that he fell in love with André while I wasn't even playing him. For convenience l'd added him to the Goth family so I could take pictures for the challenge story, and during a party I was concentrating on Bella and Mortimer and sort of forgot Thomas - and he found André all by himself (I never even thought of him as possibly being gay...) I had created André as a single father (widower) with a child - so it was not my idea that André would like other guys either. LOL!! I just love it when these things happen as if my Sims have minds of their own. (Gerd) 
Gerd's tale of Sims with "minds of their own" is more the norm than an exception in the interview material, and the kind of autonomy described here is something that the informants' cherish highly. So, while being in control gives satisfaction, letting go of control seems to be even more gratifying. At the point where players' cede control, Sims become fully realised "Others", agents who are their own persons with their own projects and life trajectories:

I love it when a sim does something autonomously that perfectly expresses who he/she is, i.e., that matches up with his/her personality. I also love it when a sim does something autonomously that fits in with whatever storyline is developing. And I love it when a sim surprises me with an unexpected moment. (Dorothy)

As expressed here by Dorothy, it is through autonomous acts that Sims come into their own. This process lets Sims become simulated Others, and this is what makes them truly relatable (Bauman, 2003, pp. 6-7). The second element of the utopia of control, then, plays with the fantasy of relating and belonging, of daring to let go and go with the flow. This seems to be at once the less visible and most pronounced utopic element in the accounts of gameplay.

Experimentation with taking and ceding control are regarded as central in much of the literature on play. This theme, for instance, is pronounced throughout Brian Sutton-Smith's wonderful work The ambiguity of play (2001). It can, likewise, be argued that central in Johan Huizinga's ritualistic understanding of play (1992) is precisely an eternal human struggle to deal with agency and the lack thereof. Within psychodynamic theory, play is related to the child's development of a self. Thus, both Sigmund Freud (1948) and Donald Winnicott (2012) focus on how, through the playful taking and ceding of control, children learn to handle or, at least, try to grapple with detachment from their carers. All these highly different treatments of play seem to agree that playful activity allows players a means for engaging with deeply serious and fundamental questions of being capable agents in a contingent world within a somewhat bounded yet not necessarily safe sphere (Geertz, 1973; Malaby, 2007).

\section{Emotions and systems}

Despite Dyer's assertion that entertainment only gives access to a sense of the utopic rather than engaging a better society as a model or system, I will argue on the basis of these players' accounts that TS2 and TS3 do, in fact, offer an opportunity to experiment with the latter as well:

There are other things that I idealise intentionally, just because I don't really want to write about things that upset me. Racism and homophobia don't exist in my hood, because I wish they didn't exist in the real world. So I have just as many interracial couples as I do "lookalikes" and I never write anything about it in the story. I have written about a couple of 
parents having trouble coming to terms with their gay kids but not in a hateful way. It was more that they were surprised and unsure how to proceed. In general, gay people have it just as easy as straight people in my game. My gay couples get married, not joined and they can even get married in a church if they want to. (Irene)

As in the example of Irene above, the games give players an opportunity to reflect about current society and, in their own gameplay, to invoke changes regarding conditions that they find unjust or wrong. Marion articulates this as being "confronted with the choice to engage in critique the minute your start the game". She elaborates:

\footnotetext{
When the Sims 2 offered a range of ethnicities in names and the ability create more nuanced faces you had to decide whether to make interracial or ethnic families, etc. I know a lot of people were frustrated that the game randomly mixed names of different ethnicities with Sims who didn't match. I had to confront my own desire to have consistency in themes with what the game throws together. I thought it was good for us all. (Marion)
}

One element that may invite reflexivity, then, is the often incoherent juxtapositions created by the games. An extreme openness for configuration is, likewise, a particular quality of playable media with many deniable elements (Leino, 2007), such as TS2 and TS3. They do not merely let players interpret and fill in the blanks or react in strictly choreographed action sequences that do not leave much time for thought. Additionally, they require continuous decision-making and engagement with the systems behind the surface expression. In the words of Ted Friedman, "computer games reveal their own constructedness to a much greater extent than more traditional texts" (1999, not paginated). Importantly, the games extend an invitation to question what exists, but it is not something that happens automatically. The games may just as well be used to reproduce the current order as to problematise it. The potential for critique, for moving beyond sensations of utopia, is precisely a potential dependent on the players for its actualisation.

\section{Conclusion}

How can we begin to understand the paradox that players seek respite from everyday chores by playing games that, to a great degree, simulate the same domain? Here, I have argued that the notions of realism and fantasy linked to media pleasures may help unlock this seeming contradiction. The relatability of the games and their everyday setting with its focus on relations, consumption, work, and family life appear to be the first cause of attraction. The "realistic" elements appear to be central for the players in that regard. In particular, emotional realism and authentic-looking buildings aid the informants in defocusing from the drudgery of everyday living despite the centrality of chores in the gameplay. In this case, then, realistic gameplay tends to centre on relations and special moments in life, while the day-to-day routine is downplayed. 
The realistic elements in the games can be seen as a bridge to fantasy, dreaming of and imagining better worlds. The more pronounced utopic elements concern true love, coming to terms with loss, consumption, as well as taking and letting go of control. Of these, the last appears to be the most vital. The informants here often describe everyday life in terms of lacking control, and it makes sense to see the use of TS2 and TS3 as a way to more or less consciously explore and engage with this issue in various ways. Interestingly, letting go of control is emphasised as much as being in control. This may be seen as further negotiation of what it means to have more or less agency in an often chaotic, unjust world in which inequality prevails in many areas of life. Moreover, this ceding of control can be interpreted as a reach for the utopia of an intense and transparent community because true relations only emerge when the Other is outside control and free to relate. While playing the games is neither automatically disempowering nor subversive, TS2 and TS3 are extremely open structures that may potentially be used to negotiate the politics of everyday living.

\section{Acknowledgements}

I am grateful to all the informants who generously shared their experiences and reflections with me. I also wish to thank the anonymous reviewers as well as the participants in the TWG on playable media at the 2013 Nordicom conference for their constructive criticism and helpful comments.

\section{References}

Ang, I. (1988). Feminist desire and female pleasure: On Janice Radway's reading the romance: Women, patriarchy, and popular literature. Camera Obscura, 16, 179-90.

Ang, I. (1991). Dallas and the melodramatic imagination. In M. Landy (Ed.), Imitations of life: A Reader on Film and Television Melodrama (pp. 473-495). Detroit: Wayne State University Press.

Bauman, Z. (2003). Liquid Love: On the Frailty of Human Bonds. Cambridge: Polity Press.

Caplan, C. (1986). The Thorn Birds: Fiction, fantasy, femininity. In V. Burgin, J. Donald \& C. Caplan (Eds.), Formations of Fantasy (pp.142-166). London: Methuen.

Dyer, R. (1986 [1977]). Entertainment and utopia. In R. Altman (Ed.), Genre: The Musical: A Reader (pp. 176189). London: Routledge.

Ellis, J. (2000). Seeing Things: Television in the Age of Uncertainty. London: I. B. Tauris.

Fast, E. (2012). More than meets the eye: Transmedial entertainment as a site of pleasure, resistance and exploitation. Ph.D. thesis: Karlstad University.

Freud, S. (1948). Beyond the Pleasure Principle. (C. Hubback, Trans.). London: Hogarth Press.

Friedman, T. (1999). The semiotics of SimCity. First Monday, 4(4). Retrieved from http://ojs-prod-lib.cc.uic. edu/ojs/index.php/fm/article/view/660/575\#f3.

Geertz, C. (1973). Notes on the Balinese cockfight. In The Interpretation of Cultures: Selected Essays (pp. 412454). New York: Basic Books.

Gilligan, V. (2008). Breaking Bad. Culver City: Sony Pictures Television. 
Harrington, C.L. \& Bielby, D. (1995). Soap Fans: Pursuing Pleasure and Making Meaning in Everyday Life. Philadelphia: Temple University Press.

Hermes, J. (1995). Reading Women's Magazines: An Analysis of Everyday Media Use. Cambridge: Polity Press. Hermes, J. (2005). Re-reading Popular Culture. Oxford: Blackwell Publishing.

Highmore, B. (2002a). Everyday Life and Cultural Theory: An Introduction. London: Routledge.

Highmore, B. (2002b). Introduction: Questioning everyday life. In B. Highmore (Ed.), The Everyday Life Reader

(pp. 1-34). London: Routledge.

Hine, C. (2000). Virtual Ethnography. London: Sage Publications.

Huizinga, J. (1992/1950). Homo Ludens: A Study of the Play Element in Culture. Boston: The Beacon Press.

Iversen, S. (2013). Playing with Sims as a space of one's own. Feminist Media Studies, DOI:10.1080/14680777 .2013 .816332 .

Iversen, S. (forthcoming). Game love at play in The Sims 2 and 3. In J. Enevold and E. MacCallum Steward

(Eds.), The Game Love Reader. Jefferson: McFarland.

Jenkins, H. (1992). Textual Poachers: Television Fans and Participatory Culture. New York: Routledge.

Kaillio, K., Mäyrä, F., \& Kaipainen, K. (2011). At least nine ways to play: Approaching gamer mentalities. Games and Culture, 6 (4): 237-353.

Kateb, G. (1963). Utopia and Its Enemies. New York: The Free Press of Glencoe.

Kivits, J. (2005). Online interviewing and the research relationship. In C. Hine (Ed.), Virtual Methods: Issues in Social Research on the Internet (pp. 35-49). Oxford: Berg Publishers.

Kozinets, R. (2010). Netnography: Doing Ethnographic Research Online. Los Angeles: Sage.

Leino, O. (2007). Emotions about the deniable/undeniable: Sketch for a classification of game content as experienced. In A. Baba (Ed.), Situated Play: Proceedings of the Third International Conference of the Digital Games Research Association (pp. 113-117). Tokyo: University of Tokyo.

Malaby, T. (2007). Beyond play: A new approach to games. Games and Culture, 2(2): 95-113.

Maxis. (2000). The Sims. Electronic Arts.

Maxis. (2004). The Sims 2. Electronic Arts.

Miles, M., Huberman, A. \& Saldaña, J. (2013). Qualitative Data Analysis: A Methods Sourcebook. Los Angeles: Sage.

Miller, T. (2007). Cultural Citizenship: Cosmopolitanism, Consumerism, and Television in a Neoliberal Age. Philadelphia: Temple University Press.

Nutt, D. \& Railton, D. (2003). The Sims: Real life as genre. Information, Communication \& Society, 6(4), $577-$ 592.

O'Connor, B. \& Klaus, E. (2000). Pleasure and meaningful discourse: An overview of research issues. International Journal of Cultural Studies, 3(3), 369-387.

Radway, J. (1991 [1984]). Reading the Romance: Women, Patriarchy, and Popular Literature. Chapel Hill: University of North Carolina Press.

Sihvonen, T. (2011). Players Unleashed: Modding The Sims and the Culture of Gaming. Amsterdam: Amsterdam University Press.

Sutton-Smith, B. (2001/1997). The Ambiguity of Play. Cambridge: Harvard University Press.

The Sims Studio. (2009). The Sims 3. Electronic Arts.

Tychsen, A., Brolund, T. \& Hitchens, M. (2008). Motivations for play in computer role-playing games. Proceedings of Future Play 2008 (pp. 57-64). New York: ACM.

Weber, M. (2011 [1920]). The Protestant Ethic and the Spirit of Capitalism (S. Kahlberg, Trans.). New York: OUP USA.

Winn, J. \& Heeter, C. (2009). Gaming, gender and time: Who makes time to play? Sex Roles, 61, 1-13.

Winnicott, D. (2012 [1971]). Playing and Reality. New York: Routledge. 
Article: Paradox and pleasure

Wirman, H. (2011). Playing The Sims 2: Constructing and negotiating woman game player identities through the practice of "skinning". Ph.D. thesis: University of the West of England.

\section{Notes}

1 In order to protect the participants, their names, screen names, custom Sims and worlds appear under pseudonym. For the same reason, the recruitment forum is not named here.

2 The TS2 players are Celia, Dorothy, Eva, Heidi, Irene and Katherine, while Anna, Betty, Felicity, Gerd, Joan, Lisa and Marion mainly play TS3.

Sara Mosberg Iversen

Assistant Professor, Ph.D.

Department for the Study of Culture

University of Southern Denmark

siv@sdu.dk 